\title{
Controlling Non-Native B12 Reactivity and Catalysis in the Transcription Factor CarH
}

Xinhang Yang, Benjamin H. R. Gerroll, Yuhua Jiang, Amardeep Kumar, Yasmine S. Zubi, Lane A. Baker, Jared C. Lewis*

Department of Chemistry, Indiana University, Bloomington, IN 47405, USA

\begin{abstract}
Vitamin B12 derivatives catalyze a wide range of organic transformations, but B12-dependent enzymes are underutilized in biocatalysis relative to other metalloenzymes. In this study, we engineered a variant of the transcription factor $\mathrm{CarH}$, called $\mathrm{CarH}^{*}$, that catalyzes styrene $\mathrm{C}-\mathrm{H}$ alkylation with improved yield and selectivity relative to B12 itself. While the native function of CarH involves transcription regulation via AdoCbl $\mathrm{Co}(\mathrm{III})$-carbon bond cleavage and $\beta$-hydride elimination to generate 4',5'-didehydroadenosine, $\mathrm{CarH}^{*}$-catalyzed styrene alkylation proceeds via non-native oxidative addition and olefin addition coupled with a native-like $\beta$-hydride elimination. Mechanistic studies on this reaction echo findings from earlier studies on AdoCbl homolysis under strong cage conditions to suggest that $\mathrm{CarH}^{*}$ can enable non-native radical chemistry with improved selectivity relative to B12 itself. These findings lay the groundwork for the development of B12-dependent enzymes as catalysts for a wide range of non-native transformations.
\end{abstract}

\section{Keywords}

B12, cobalamin, C-H functionalization, biocatalysis, non-native enzyme catalysis

\section{Introduction}

Derivatives of vitamin B12 comprise a family of cobalt corrin complexes (cobalamins) with different axial ligands that confer unique reactivity to these complexes in their roles as enzyme cofactors (Figure 1A). ${ }^{1}$ B12-dependent enzymes include adenosylcobalamin-dependent (AdoCbl) isomerases, ${ }^{2}$ methylcobalamin-dependent (MeCbl) methyltransferases, ${ }^{3}$ and dehalogenases ${ }^{4}$. Within these classes, variation of the axial ligand distal to the substrate binding pocket is also observed. The dimethylbenzimidazole $(\mathrm{dmb})$ ligand of B12 can be bound to the cobalt center (dmb-on), as in Class II B12-dependent isomerases, or unbound (dmb-off), as in Class I B12dependent isomerases. ${ }^{2}$ Alternatively, a distal histidine residue from the protein scaffold can bind the cobalt center (His-on). ${ }^{5}$ These structural variations and the unique interactions between cobalamins and their respective enzyme scaffolds enable these naturally occurring organometallic complexes to engage substrates via both radical and polar chemistry (e.g. isomerization and methylation, respectively). ${ }^{6}$

When removed from their natural protein scaffolds, cobalamins can catalyze an even broader range of $\mathrm{C}-\mathrm{C}$ bond forming reactions than observed in nature. ${ }^{7}$ Moreover, Co(III)-alkyl complexes analogous to AdoCbl and $\mathrm{MeCbl}$ have been proposed as intermediates in reductive dehalogenation, ${ }^{8}$ alkyl halide and alkene coupling reactions, ${ }^{9}$ and a number of transformations involving alkenyl $\mathrm{C}-\mathrm{H}$ functionalization ${ }^{10-12}$. These reactions proceed via a highly nucleophilic $\mathrm{Co}(\mathrm{I})$ intermediate $^{13}$ that undergoes oxidative addition with a variety of organic electrophiles to generate Co(III)-alkyl complexes. ${ }^{14}$ These complexes can react via radical coupling or olefin addition pathways to generate different organic products. Unlike enzymatic transformations, 
however, product mixtures are typically obtained due to homolysis of the Co(III)-alkyl bond and subsequent free radical chemistry, and very few of these reactions can be achieved with catalyst controlled selectivity. ${ }^{7} \mathrm{We}$ were therefore drawn to the potential non-native reactivity of vitamin B12-containing proteins and the control that protein scaffolds could exert over the reactivity of B12-derived Co-alkyl intermediates.

Homolysis of the Co(III)-carbon bond of the AdoCbl cofactor in B12-dependent isomerases (Figure 1B) forms the basis of a variety of $\mathrm{C}-\mathrm{H}$ functionalization reactions that proceed via $\mathrm{C}-\mathrm{H}$ abstraction by the 5'-deoxyadenosyl radical (Ado•). ${ }^{2}$ We reasoned that similar active site localization of a Co(III)-alkyl complex generated from the reaction of the Co(I) form of a suitable B12-containing protein with simple organic electrophiles could be used to confer selectivity to a variety of cobalt-catalyzed transformations. The light-dependent transcription factor $\mathrm{CarH}^{15}$ piqued our interest as a candidate enzyme due to its proposed mechanism involving $\beta$-hydride elimination of an AdoCbl intermediate (Figure 1B) ${ }^{16}$. If an analogous intermediate could be accessed via initial alkylation of $\mathrm{Co}(\mathrm{I})$ with a simple alkyl electrophile lacking $\beta$-hydrogen substituents, ${ }^{14}$ reaction of the resulting $\mathrm{Co}(\mathrm{III})$-alkyl with a reagent capable of generating an intermediate with $\beta$-hydride substituents could enable olefin formation ${ }^{17}$ and catalyst turnover.

In considering reactions that could test this hypothesis, we were drawn to a study by Gryko involving $\beta$-alkylation of styrenes using alkyl diazoacetates catalyzed by the hexamethyl ester of $\mathrm{CNCbl}^{10}$. This reaction was proposed to proceed via radical addition of a $\mathrm{Co}$ (III)-carboxymethyl species to styrene followed by $\beta$-hydride elimination (Figure 1C), the latter mirroring a proposed radical pathway for native $\mathrm{CarH}$ reactivity ${ }^{16}$ (a polar mechanism was also proposed $)^{16,18}$. An undesired alkane byproduct also forms under the reaction conditions $(\sim 2: 1)$ and was proposed to result from free radical side reactions. Herein, we show that an engineered variant of CarH corrects this issue and increases styrene alkylation yields relative to B12 alone by stabilizing Co(III)-alkyl species generated from different organic electrophiles to enable selective reaction of these species with styrenes. This non-native reactivity suggests that B12-containing proteins could serve as catalysts for a wide range of Co-catalyzed transformations.

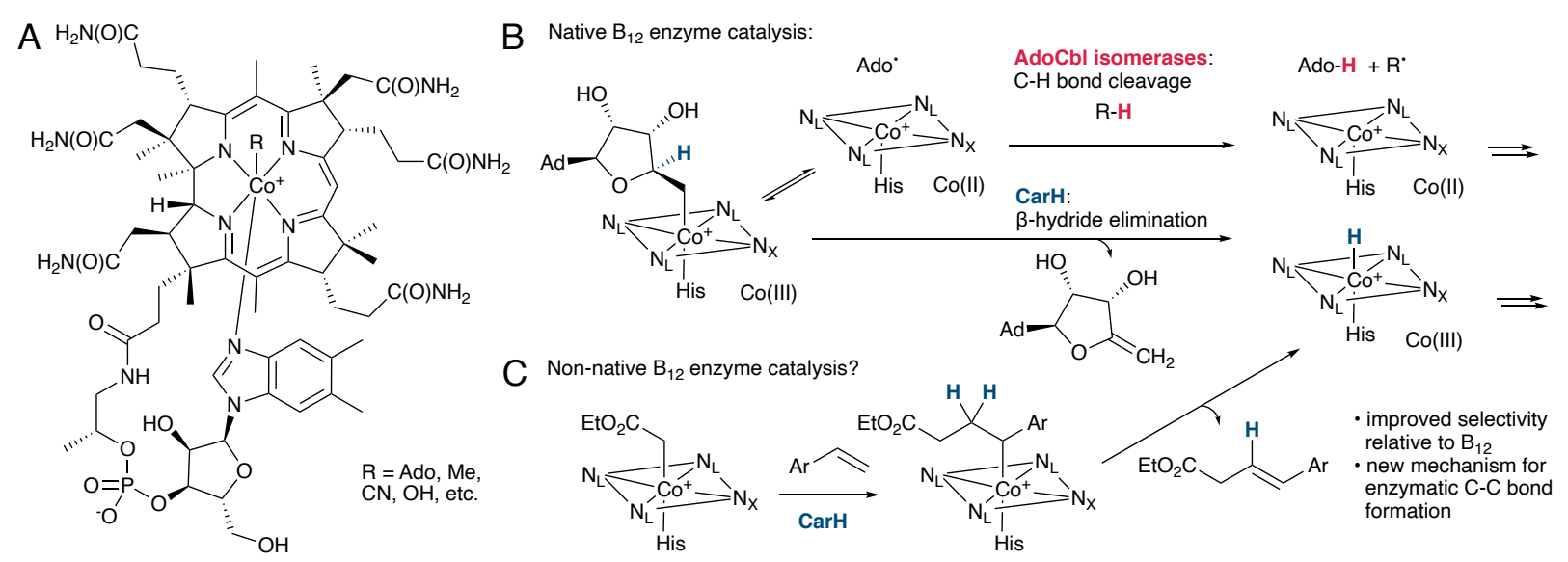

Figure 1. (A) Structures of representative cobalamins. (B) Comparison of the intermolecular C-H abstraction observed for AdoCbl-dependent isomerases ${ }^{2}$ and a proposed radical-based $\beta$-hydride elimination mechanism for $\mathrm{CarH}(\mathrm{Ad}=\text { adenine })^{16}$. (C) Potential CarH-catalyzed styrene $\mathrm{C}-\mathrm{H}$ functionalization involving $\beta$-hydride elimination. 


\section{Results}

CarH is B12-dependent transcription factor that exploits a remarkable exaptation of AdoCbl $\mathrm{Co}$ (III)-carbon bond cleavage ${ }^{18,19}$ to enable light-activated gene expression, ${ }^{15}$ rather than the more common radical rearrangement processes catalyzed by other AdoCbl-dependent enzymes (Figure 1B $)^{2}$. In its AdoCbl-bound form, CarH forms a tetramer that binds DNA to repress transcription of carotenoid biosynthesis genes that protect organisms from light damage. ${ }^{20}$ Upon exposure to light, the $\mathrm{Co}(\mathrm{III})$-carbon bond of AdoCbl most likely undergoes homolytic cleavage ${ }^{19}$ (though heterolytic cleavage has also been proposed ${ }^{18}$ ), leading to loss of $4^{\prime}, 5^{\prime}$-anhydroadenosine ${ }^{16}$ and formation of bis-His cobalamin ${ }^{18}$, which causes a conformational change in the enzyme that favors monomer formation, DNA dissociation, and transcription activation. The structure of CarH comprises a C-terminal domain that binds AdoCbl in a His-on fashion (H177); a four-helix cap above the AdoCbl cofactor; and a N-terminal DNA binding domain. ${ }^{20}$

We reasoned that apo CarH could be reconstituted with hydroxocobalamin ${ }^{18}$ so that the vacant Ado binding site could be used for substrate binding and that His-on cobalamin binding would allow for modulation of reactivity via distal axial ligand variation. We first examined CarH from Thermus thermophilus (TtCarH), but its low solubility complicated characterization. This issue was addressed by fusing a N-terminal His 6 -MBP tag to the enzyme, which we also presumed would disrupt potential tetramer formation. A histidine residue (H132) near the Ado binding pocket was mutated to glycine to preclude its binding to $\mathrm{B} 12^{18}$ and potential reactions with added electrophiles. Apo MBP-TtCarH H132G (hereafter CarH*) was expressed in E. coli $(20 \mathrm{mg} / \mathrm{L})$, purified by NiNTA chromatography, and reconstituted with a three-fold excess of hydroxocobalamin. The enzyme was purified by size-exclusion chromatography to provide the desired cobalamin-bound form of $\mathrm{CarH}^{*}$ as a monomer in good yield ( $\left.84 \%\right)$.

The feasibility of reducing $\mathrm{CarH}^{*}$ to its $\mathrm{Co}(\mathrm{I})$ form and alkylating this species with different electrophiles was next evaluated. Several chemical reductants can be used to generate the Co(I) oxidation state of B12, ${ }^{14}$ but most of these are heterogeneous or absorb UV-vis light at wavelengths that overlap with diagnostic absorptions for the different oxidation states of B12. We therefore turned to UV-vis absorption spectroelectrochemistry to generate the $\mathrm{Co}(\mathrm{I})$ form of $\mathrm{CarH}^{*}$ and monitor its reaction with ethyl diazoacetate (EDA, Figure 2A), ethyl chloroacetate (ECA), and $p$ methoxystyrene. At a potential of $-1.5 \mathrm{~V}$, reduction of $\mathrm{CarH}^{*}$ occurred as evidenced by the appearance of a peak at $388 \mathrm{~nm}$, consistent with the $\mathrm{Co}(\mathrm{I})$ form of the enzyme (B), and concomitant loss of a peak at $357 \mathrm{~nm}$, associated with the Co(III) form (A) (Figure 2B). ${ }^{21}$ Addition of either EDA or ECA to $\mathbf{B}$ led to rapid $(<15 \mathrm{~s})$ formation of the Co(II) form $(\mathbf{C})$, as indicated by a peak at $475 \mathrm{~nm}$ (Figure 2C, D). A gradual disappearance of the Co(II) form and appearance of a second $\mathrm{Co}(\mathrm{III})$ species, assigned as $\mathbf{E}$ (presumably via the intermediacy of $\mathbf{D}$ ), ${ }^{21}$ then occurred before reduction of the sample back to $\mathrm{Co}(\mathrm{I})$. The absorbances associated with $\mathbf{E}$ were red shifted by roughly $18 \mathrm{~nm}$ and broadened relative to those associated with $\mathbf{A}$, consistent with previously reported spectra of B12 complexes with increasingly less electronegative axial ligands ${ }^{22}$ (from oxygen to carbon in the current case). It should also be noted that $\mathrm{Co}$ (II) could also be formed from reduction of proton in water by $\mathbf{B},{ }^{23}$ and $\mathbf{E}$ could form via two-electron oxidative addition of $\mathbf{B}$, so the relevance of the observed $\mathrm{Co}$ (II) peaks to the formation of $\mathbf{E}$ cannot be definitively established from these data. No significant buildup of peaks consistent with a Co(III) complex were observed upon addition of styrene (Figure 2E). Similar spectra were observed for the reaction of ECA with hydroxycobalamin at $-1.2 \mathrm{~V}$, but the rates of the reactions were much faster, presumably due to 
improved access of the B12 cofactor to the electrode in the absence of the CarH* protein components (Supplementary Figure S1C). Interestingly, a peak corresponding to a Co(III) species following addition of EDA to the Co(I) form of hydroxycobalamin was not red-shifted as it was for $\mathrm{CarH}^{*}$, perhaps suggesting different oxidative addition mechanisms for B12 in solution versus within $\mathrm{CarH}^{*}$ (Supplementary Figure S1B).

A
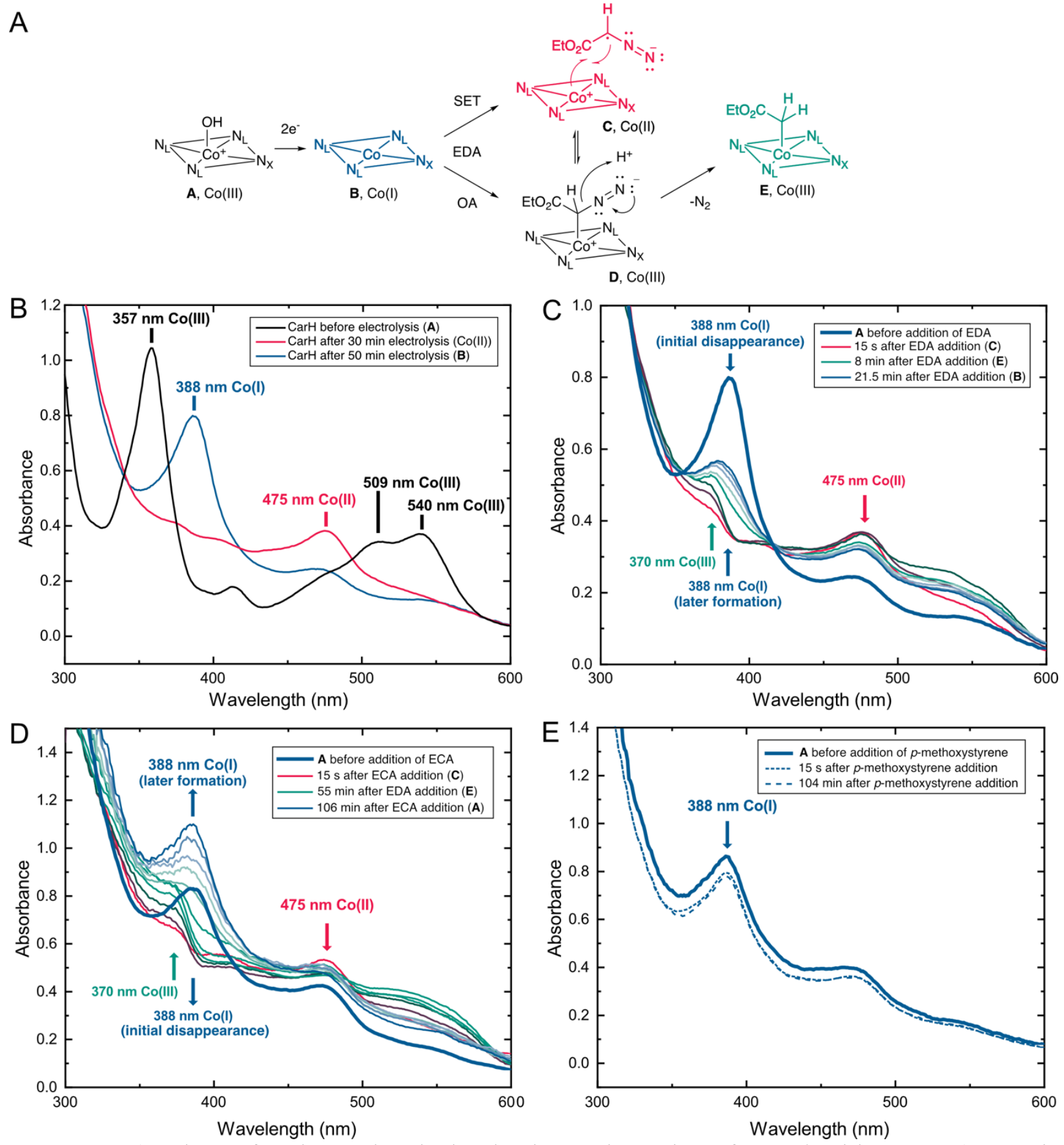

Figure 2. A) Scheme for electrochemical reduction and reaction of CarH* with EDA. B) UV-vis absorbance spectra for the $\mathrm{Co}(\mathrm{III}), \mathrm{Co}(\mathrm{II})$, and $\mathrm{Co}(\mathrm{I})$ forms of $\mathrm{CarH}^{*}(22 \mu \mathrm{M})$ generated following electrolysis for the specified times. Arrows indicate direction of absorbance change for different species. C-E) UV-vis absorbance spectra for $\mathrm{CarH}^{*}(22 \mu \mathrm{M})$ following addition of $22 \mu \mathrm{M}$ EDA (C), ECA (D), or styrene (E). 
Encouraged by the observation of a Co(III) species consistent with ethyl carboxymethyl intermediate $\mathbf{E}$ envisioned in Figure 1, we next sought to establish whether subsequent reaction of this species would occur in the presence of styrene. Toward this end, $p$-methoxystyrene and EDA were incubated with $4.4 \mathrm{~mol} \%$ of $\mathrm{CarH}^{*}$ and excess Ti(III) citrate, which has been used to access $\mathrm{Co}(\mathrm{I})$ in a variety of Co-catalyzed transformations ${ }^{7}$. Alkene 1 a formed in $57 \%$ yield, constituting 13 turnovers under optimized reaction conditions (Table 1, entry 1). A small amount of alkane 2a also formed (1a:2a $=19: 1)$. Significantly lower yield of $\mathbf{1 a}(22 \%)$ and lower selectivity for 1a over 2a was obtained using hydroxocobalamin (1a:2a $=4: 1$, Table 1, entry 2). No 1a or $\mathbf{2 a}$ was observed for two other B12-dependent enzymes, MetH or hMUT (Table 1, entries 3 and 4), ${ }^{6}$ construction of which are described in the SI. When reduced to the $\mathrm{Co}$ (II) state using $\mathrm{Na}_{2} \mathrm{~S}_{2} \mathrm{O}_{4}$ in the presence of EDA and $p$-methoxystyrene, these enzymes give trace amounts of cyclopropanation product 3a, ${ }^{24}$ but $\mathrm{CarH}^{*}$ gave no detectable cyclopropanation activity (Table S2). Together, these results highlight the unique capability of $\mathrm{CarH} *$ to catalyze styrene $\mathrm{C}-\mathrm{H}$ functionalization.

Table 1. Styrene alkylation catalyzed by B12 and different B12-dependent enzymes.

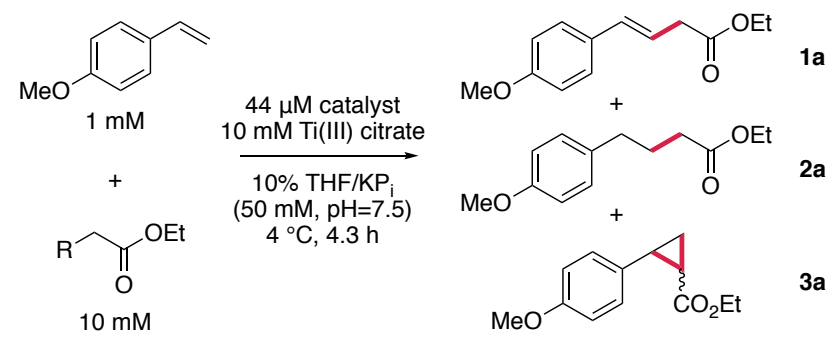

\begin{tabular}{ccccc}
\hline Entry & Catalyst & $\mathbf{1 a}(\%)^{\mathrm{a}}$ & $\mathbf{2 a}(\%)$ & $\mathbf{3 a}(\%)$ \\
\hline 1 & $\mathrm{~B}_{12}$ & 22 & 5 & 0 \\
2 & $\mathrm{CarH}^{*}$ & 57 & 3 & 0 \\
3 & MetH & 0 & 0 & 0 \\
4 & $h$ MUT & 0 & 0 & 0 \\
\hline
\end{tabular}

${ }^{a}$ Yields determined by GC/MS analysis of crude reaction mixtures relative to 3,3',5,5'tetramethylbenzidine internal standard.

Several additional styrenes and diazo substrates were next examined to evaluate the substrate specificity of $\mathrm{CarH}^{*}$-catalyzed styrenyl $\mathrm{C}-\mathrm{H}$ functionalization (Table 2). $\mathrm{CarH}^{*}$ variants containing active site mutations were also evaluated (Figures S25, S26), but only the W131F variant provided substantially higher conversions in some cases (Table 2, Entries 3 and 6, Figure S26). Modest-good conversion was obtained for electron rich styrenes, though excellent conversion was observed for an acetamido-substituted styrene (Table 2, entry 4), and the enzyme exhibits a preference for relatively small styrenes and diazoacetates and diazoacetamides. No activity was observed for donor-acceptor or acceptor-acceptor carbene precursors, again highlighting the requirement for relatively small substrates, though phenyl diazoacetate and diethyl diazoacetamide were both tolerated. These results indicate that the protein scaffold plays a role in regulating substrate access to the $\mathrm{B} 12$ cofactor in $\mathrm{CarH}^{*}$ and that the enzyme is not simply serving as a radical initiator as $\mathrm{B} 12$ does in the absence of the protein scaffold. 
Table 2. Substrate scope of $\mathrm{CarH}^{*}$-catalyzed styrene alkylation

\begin{tabular}{|c|c|c|c|c|c|}
\hline \multirow{2}{*}{ Entry } & \multirow{2}{*}{1} & \multirow{2}{*}{$\mathrm{R}^{1}$} & \multirow{2}{*}{$\mathrm{R}^{2}$} & \multicolumn{2}{|c|}{ Yield $(\%)^{\mathrm{a}}$} \\
\hline & & & & B12 & $\mathrm{CarH}^{*}$ \\
\hline 1 & $\mathbf{a}$ & $\mathrm{OMe}$ & $\mathrm{OEt}$ & 22 & 57 \\
\hline 2 & b & $\mathrm{OEt}$ & $\mathrm{OEt}$ & 11 & 22 \\
\hline 3 & $\mathbf{c}^{\mathrm{b}}$ & $\mathrm{NMe}_{2}$ & $\mathrm{OEt}$ & 20 & 49 \\
\hline 4 & d & NHAc & $\mathrm{OEt}$ & 15 & 97 \\
\hline 5 & e & $\mathrm{Me}$ & $\mathrm{OEt}$ & 10 & 25 \\
\hline 6 & $f^{b}$ & $\mathrm{H}$ & $\mathrm{OEt}$ & 8 & 29 \\
\hline 7 & g & $\mathrm{OMe}$ & $\mathrm{OPh}$ & 13 & 32 \\
\hline 8 & h & $\mathrm{OMe}$ & $\mathrm{NEt}_{2}$ & 14 & 68 \\
\hline
\end{tabular}

aYields determined by GC/MS analysis of crude reaction mixtures relative to 3,3',5,5'tetramethylbenzidine internal standard. ${ }^{b}$ Reactions were performed using $\mathrm{CarH}^{*} \mathrm{~W} 131 \mathrm{~F}$.

To gain further insight into the relative reactivity of $\mathrm{CarH}^{*}$ and the $\mathrm{B} 12$ cofactor, the rates for reactions of $p$-methoxystyrene (1) and $\beta, \beta-\mathrm{d}_{2}-p$-methoxystyrene $\left(\beta, \beta-\mathrm{d}_{2}-1\right)$ with EDA catalyzed by $\mathrm{CarH}^{*}$ or hydroxocobalamin were next measured in $\mathrm{H}_{2} \mathrm{O}$ (Table 3, Entries 1 and 3). Due to poor substrate solubility, initial rates $\left(\mathrm{k}_{\mathrm{obs}}\right)$ could only be acquired within a narrow concentration range that prohibited Michaelis-Menten kinetic analysis. Comparing $\mathrm{k}_{\mathrm{obs}}$ using $0.5 \mathrm{mM}$ substrate, however, showed that $\mathrm{CarH}^{*}$ provides $\sim 5 \mathrm{x}$ rate acceleration relative to hydroxocobalamin, consistent with the higher yields obtained from the enzyme under optimized conditions (Table 2). Normal deuterium kinetic isotope effects were observed for styrene alkylation catalyzed by CarH* and B12 (e.g. $\mathrm{k}_{\mathrm{H}} / \mathrm{k}_{\mathrm{D}}=1.85$ and 2.15 , respectively, Table 3 , Entry 1 ). This finding indicates that $\mathrm{C}$ $\mathrm{H}$ cleavage occurs in the rate-limiting step of the reaction, as would be expected if $\beta$-hydride elimination was at least partially rate-limiting.

The rates for the analogous reactions of 1 and $\beta, \beta-\mathrm{d}_{2}-1$ in $50 \% \mathrm{D}_{2} \mathrm{O} / \mathrm{H}_{2} \mathrm{O}$ were also examined to probe the susceptibility of styrene alkylation to solvent isotope effects (SIEs) ${ }^{25}$. A normal SIE is observed for hydroxocobalamin $\left(\mathrm{k}_{\mathrm{H} 2 \mathrm{O}} / \mathrm{k}_{\mathrm{D} 2 \mathrm{O}}>1.4\right)$, while an inverse SIE is observed for $\mathrm{CarH}^{*}$ $\left(\mathrm{k}_{\mathrm{H} 2 \mathrm{O}} / \mathrm{k}_{\mathrm{D} 2 \mathrm{O}}<0.9\right)($ Table 3 , entries $1 / 2$ and $3 / 4)$. To identify sites in intermediates involved in styrene alkylation that undergo $\mathrm{H} / \mathrm{D}$ exchange during the reaction and that might therefore play a role in the observed SIEs, GC/MS was used to analyze products from reactions conducted in $50 \%$ $\mathrm{D}_{2} \mathrm{O} / \mathrm{H}_{2} \mathrm{O}$. While incorporation of a single deuterium into Co(III)-alkyl intermediate $\mathbf{E}$ was expected based on the mechanism shown in Figure $2 \mathrm{~A}$, a mixture of $\mathrm{d}_{1}$ - and $\mathrm{d}_{2}$-products were obtained, and higher deuterium incorporation was observed for the $\mathrm{CarH}^{*}$-catalyzed reaction $(78 \%$ conversion to $\mathrm{d}_{1}$ - and $\mathrm{d}_{2}$-products vs $66 \%$ for $\mathrm{B} 12$ ). No $\mathrm{H} / \mathrm{D}$ exchange was observed in the reaction of $\mathrm{d}_{8}$-styrene in $\mathrm{H}_{2} \mathrm{O}$, indicating that $\mathrm{H} / \mathrm{D}$ exchange occurs at the $\alpha$-carbon of intermediate $\mathbf{E}$. 
Table 3. Deuterium kinetic isotope effects and solvent isotope effects for styrene alkylation reactions catalyzed by $\mathrm{B} 12$ and $\mathrm{CarH}^{*}$.

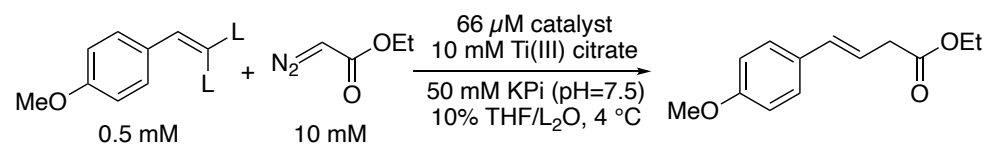

\begin{tabular}{|c|c|c|c|c|c|c|c|c|c|c|}
\hline \multirow[t]{2}{*}{ Entry } & \multirow[t]{2}{*}{ Styrene } & \multirow[t]{2}{*}{ Diazo } & \multirow[t]{2}{*}{ Solvent } & \multicolumn{2}{|c|}{$\begin{array}{l}\text { Initial Rate } \\
\left(\mu \mathrm{M} \cdot \mathrm{min}^{-1}\right)\end{array}$} & \multirow[t]{2}{*}{$\begin{array}{c}\mathrm{k}_{\mathrm{CarH}}^{*} / \\
\mathrm{k}_{\mathrm{B} 12}\end{array}$} & \multicolumn{2}{|c|}{$\mathrm{k}_{\mathrm{H}} / \mathrm{k}_{\mathrm{D}}$} & \multicolumn{2}{|c|}{$\mathrm{k}_{2} \mathrm{O} / \mathrm{k}_{50 \%} \mathrm{D}_{2} \mathrm{O}$} \\
\hline & & & & $\mathrm{CarH}^{*}$ & B12 & & $\mathrm{CarH}^{*}$ & B12 & CarH* & $\mathrm{B} 12$ \\
\hline 1 & 1 & EDA & $\mathrm{H}_{2} \mathrm{O}$ & $\begin{array}{c}8.87 \\
(0.43)\end{array}$ & $\begin{array}{c}1.66 \\
(0.08)\end{array}$ & $\begin{array}{c}5.34 \\
(0.37)\end{array}$ & $\begin{array}{c}1.85 \\
(0.15)\end{array}$ & $\begin{array}{c}2.15 \\
(0.15)\end{array}$ & 0.86 & 1.67 \\
\hline 2 & 1 & EDA & $\begin{array}{c}50 \% \\
\mathrm{D}_{2} \mathrm{O} / \mathrm{H}_{2} \mathrm{O}\end{array}$ & $\begin{array}{l}10.27 \\
(0.63)\end{array}$ & $\begin{array}{c}0.99 \\
(0.05)\end{array}$ & $\begin{array}{l}10.37 \\
(0.82)\end{array}$ & $\begin{array}{c}1.63 \\
(0.11)\end{array}$ & $\begin{array}{c}1.86 \\
(0.19)\end{array}$ & $(0.07)$ & $(0.11)$ \\
\hline 3 & $\beta, \beta-\mathrm{d}_{2}-1$ & EDA & $\mathrm{H}_{2} \mathrm{O}$ & $\begin{array}{c}4.77 \\
(0.28)\end{array}$ & $\begin{array}{c}0.77 \\
(0.04)\end{array}$ & $\begin{array}{c}6.19 \\
(0.50)\end{array}$ & $x^{2}-5$ & 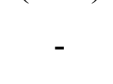 & 0.7 & 1.45 \\
\hline 4 & $\beta, \beta-\mathrm{d}_{2-1}$ & EDA & $\begin{array}{c}50 \% \\
\mathrm{D}_{2} \mathrm{O} / \mathrm{H}_{2} \mathrm{O}\end{array}$ & $\begin{array}{c}6.29 \\
(0.25)\end{array}$ & $\begin{array}{c}0.53 \\
(0.05)\end{array}$ & $\begin{array}{c}11.86 \\
(1.86)\end{array}$ & - & - & $(0.07)$ & $(0.15)$ \\
\hline
\end{tabular}

Further differences in $\mathrm{CarH}^{*}$ and hydroxycobalamin catalysis were revealed by monitoring methoxystyrene consumption in reactions with and without EDA at low conversions. When the $\mathrm{CarH}^{*}$-catalyzed reaction had proceeded to give a $22 \%$ yield of 3a, $24 \%$ of the total methoxystyrene had been consumed. In the absence of EDA, however, $43 \%$ of styrene was consumed and polymethoxystyrene oligomers were observed by GPC (Supplementary Figure S2) ${ }^{9}$. During the same period of time, reactions catalyzed by hydroxocobalamin gave only 3\% yield of $3 \mathbf{a}$ and $36 \%$ of methoxystyrene consumption in the presence of EDA, and 52\% consumption of methoxystyrene in the absence of EDA.

Finally, we investigated the effects of added TEMPO on $\mathrm{CarH}^{*}$ and hydroxycobalamin-catalyzed styrene alkylation. ${ }^{26}$ As expected for a reaction involving free radical intermediates, the yields for the hydroxocobalamin-catalyzed reactions were reduced from $18 \%$ to $13 \%$ to $7 \%$ in the presence of one and five equivalents of TEMPO, respectively (Figure SX). On the other hand, CarH*catalyzed reactions were not affected by up to 5 equivalents of TEMPO. No conversion was observed for either catalyst in the presence of 20 equivalents of TEMPO, and the TEMPO adduct of the ethyl carboxymethyl radical was observed by GC/MS analysis of these reaction mixtures (Figure $\mathrm{SX})^{27}$. Both $\mathrm{d}_{1}$ - and $\mathrm{d}_{2}$-TEMPO adducts were obtained for analogous reactions conducted in $50 \% \mathrm{D}_{2} \mathrm{O} / \mathrm{H}_{2} \mathrm{O}$, consistent with the isotopic exchange at the $\alpha$-carbon noted above.

\section{Discussion}

Non-native enzyme catalysis brings the exquisite selectivity of enzymes to bear on chemical reactions that did not happen to emerge in nature. This capability can be revealed by exposing an enzyme to substrates, reagents, or conditions that are distinct from those associated with its native activity but that enable mechanistically feasible pathways involving its active site residues and cofactors. ${ }^{28}$ Particularly illustrative examples of this capability involve the use of heme enzymes as selective catalysts for carbene and nitrene insertion reactions. ${ }^{29,30}$ While cytochromes P450 are best known for catalyzing oxene insertions, non-native carbene and nitrene insertion reactions are catalyzed by several heme enzymes with dramatically improved rates and unprecedented 
selectivity relative to the analogous reactions catalyzed by heme or other iron porphyrin complexes.

The state of catalysis using vitamin B12 is similar to that employing heme and related complexes. Vitamin B12 catalyzes a broad range of reactions, including reductive olefin coupling, crosscoupling, dehalogenation, and cyclopropanation, ${ }^{7}$ but achieving catalyst control over the selectivity these reactions is challenging since the substituents of the B12 corrin ring that could interact with substrates are distal to its cobalt center (Figure 1A). B12-dependent proteins solve this problem by embedding the B12 cofactor in a chiral protein pocket that regulates substrate access to and reactivity with the cobalt center. ${ }^{1}$ As noted above, studies on the mechanism of CarH, which involves $\mathrm{Co}$ (III)-carbon bond homolysis of its AdoCbl cofactor ${ }^{18,20}$ to release 4',5'anhydroadenosine (Figure 1B) ${ }^{16}$, suggested to us that it might be uniquely suited for non-native catalysis involving an analogous $\beta$-hydride elimination (Figure $1 \mathrm{C}$ ). This hypothesis was validated by successful catalysis of styrene alkylation using EDA in the presence of $\mathrm{CarH}^{*}$.

Several findings from this effort suggest that $\mathrm{CarH}^{*}$ and related enzymes could serve as useful starting points for further exploration of non-native B12 catalysis. First, the desired activity was observed for CarH but not the extensively studied B12-dependent enzymes hMUT or MetH ${ }^{6}$. While the poor solubility of CarH initially limited the utility of this finding, this issue was addressed via fusion to MBP to generate $\mathrm{CarH}^{*}$, providing a means to explore the activity of $\mathrm{CarH}^{*}$ and perhaps homologous proteins. In addition, observation of the $\mathrm{Co}(\mathrm{I})$ form of $\mathrm{CarH}^{*}$ using UV-vis spectroelectrochemistry and conversion of this species to others consistent with Co(III)-alkyl complexes upon addition of either EDA or ECA (Figure 2C/D) indicates that this protein can be used to access the non-native $\mathrm{Co}(\mathrm{I})$ oxidation state and chemical transformations associated with it?

Most notably, however, the mechanistic studies outlined above indicate that the control exhibited by $\mathrm{CarH}$ over the reactivity of the AdoCbl cofactor ${ }^{16}$ extends to non-native reactions. The improved styrene alkylation yields and chemoselectivity of $\mathrm{CarH}^{*}$ relative to hydroxocobalamin highlight this potential. Improved chemoselectivity is illustrated by both improved production of the desired alkylated styrenes over the corresponding alkane side products under the optimized reaction conditions and, in the presence of added TEMPO, production of alkene over ethyl carboxymethyl-TEMPO adducts. Interestingly, Finke reported that ethylene glycol-induced caging of a [Ado • Cbi] pair uniquely enables $\beta$-hydride elimination to generate 4',5'-didehydroadenosine during homolysis of AdoCbi derivatives ( $\mathrm{Cbi}=$ cobinamide). Ado $\bullet$ could, however, be intercepted under strong cage conditions using high concentrations of TEMPO to yield an Ado-TEMPO adduct. ${ }^{26}$ Drennan suggested that CarH could exert a similar caging effect on Ado $\bullet$ to facilitate $\beta$ hydride elimination. ${ }^{16}$ The TEMPO trapping studies in the current study suggest that this same phenomenon results in caging of the ethyl carboxymethyl radical that would form upon homolysis of ethyl carboxymethyl-B12 intermediate $\mathbf{E}$ (Figure 2A) to enable radical addition to styrene and subsequent $\beta$-hydride elimination in preference to cage escape and radical polymerization observed for hydroxocobalamin. Despite this cage effect, high TEMPO concentrations could be used to intercept the $\alpha$-carboxymethyl radical to generate the corresponding TEMPO adduct of this compound in analogy AdoCbl system studied by Finke ${ }^{26}$. While Sension and Penner-Hahn have provided evidence that native $\mathrm{CarH}$ activity involves a concerted $\beta$-hydride elimination to generate 
4',5'-anhydroadenosine from a ${ }^{3}$ MLCT state accessed following photoexcitation, ${ }^{19}$ our reactions were conducted in the absence of light, so we presume this pathway is not operative.

Docking a geometry-optimized structure of ethyl carboxymethyl-B12 (E, Figure 2A) into apo$\mathrm{CarH}^{*}$ (Figure 3A) using RosettaLigand shows how the active site might accommodate this alkyl fragment within a narrow binding cleft (Figure 3B). Docking $p$-methoxystyrene into this structure shows how sterically undemanding styrenes could access this cleft in an orientation that places the styrene $\beta$-position approximately $3 \AA$ from the $\alpha$-carbon of $\mathbf{E}$ to enable the observed chemoselectivity. The predicted binding poses (Supplementary Figure S3) are consistent with the observation that $\alpha$-substituted diazoacetates are not tolerated but phenyldiazoacetate and $N, N$ dimethyldiazoacetamide are, since both project their substituents out of the active site. Likewise, styrene binding within the active site explains why bulky styrene substituents are not tolerated and why the even bulkier TEMPO reacts less readily with the $\mathbf{E}$ to generate the ethyl carboxymethyl adducts that form readily in the presence of hydroxycobalmin. This structure also illustrates how mutation of W131 would be expected to play a role in modulating CarH* reactivity due to its position directly above the putative styrene binding pocket.

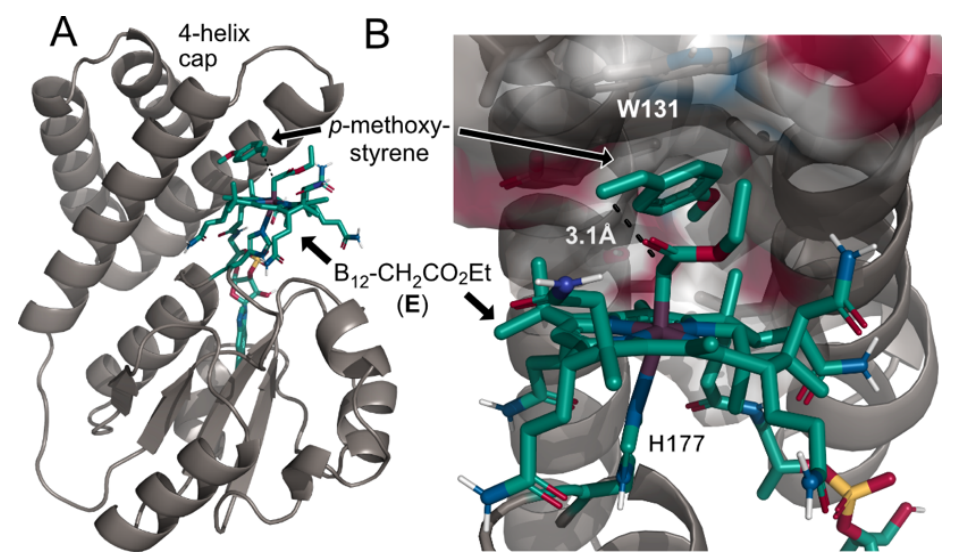

Figure 3. A) Geometry-optimized structure of ethyl carboxymethyl-B12 complex $\mathbf{E}$ (Figure 2A) docked into a structure of CarH. B) Close-up of active site showing narrow, hydrophobic substrate binding channel between two helices of the 4-helix cap of CarH (van der Waals surface rendered).

In addition to these reactivity differences, the observed isotope effects also point to the involvement of the $\mathrm{CarH}^{*}$ scaffold in modulating B12 reactivity. Similar deuterium KIEs are observed for both hydroxocobalamin and $\mathrm{CarH}^{*}$, suggesting that the rate limiting step of both reactions is the same. The different solvent isotope effects, and the fact that an inverse SIE is observed for the CarH catalyzed reaction in particular, suggest that more subtle changes in nonrate limiting steps may be responsible for the observed selectivity of $\mathrm{CarH} .{ }^{31}$ Control reactions conducted in $9 \%$ glycerol $/ \mathrm{H}_{2} \mathrm{O}$ provide similar yields at low substrate conversion to those conducted in pure water (Figure SX), indicating that the increased viscosity of $\mathrm{D}_{2} \mathrm{O}$ relative to $\mathrm{H}_{2} \mathrm{O}$ is not responsible for the inverse SIE of $\mathrm{CarH}^{*}{ }^{*}{ }^{31}$ Inverse SIEs for enzyme-catalyzed reactions are most often attributed to displacement of metal-bound waters or H/D exchange involving active site cysteine residues. ${ }^{31} \mathrm{CarH}$ does not possess the latter, and the $\mathrm{Co}(\mathrm{I})$ form of $\mathrm{B} 12$, the only form expected to have an open coordination site under the reaction conditions, would not be expected to bind water ${ }^{32}$. Inverse SIEs have also been attributed to differences in ligand binding affinity for different conformational states of an enzyme. ${ }^{33}$ Given that the four-helix cap that sits on top of the 
B12 cofactor in CarH (Figure 3) is known to undergo large conformational changes, ${ }^{20}$ we tentatively suggest that differences in the affinity in those conformation states for Co(III)-alkyl intermediates could explain the observed inverse SIEs and account for the improved selectivity of $\mathrm{CarH}^{*}$ relative to free B12. Quantitative kinetic analysis and proton inventory experiments with a suitable model system will be required to better clarify these possibilities. ${ }^{31,33}$

Putting these findings together with the original mechanistic hypothesis of Gryko, ${ }^{10}$ we propose that $\mathrm{CarH}^{*}$-catalyzed styrene alkylation proceeds via the mechanism shown in Figure 4. Catalysis is initiated by reduction of cobalamin to its $\operatorname{Co}(\mathrm{I})$ oxidation state $(\mathbf{B})$, which undergoes oxidative addition with EDA to generate intermediate E. Addition of styrene to this complex, presumably via homolysis and recombination of organic radical and Co(II) intermediates, ${ }^{17}$ would give a second Co(III)-alkyl complex. $\beta$-Hydride elimination from this species would form the observed alkene products and a $\mathrm{Co}(\mathrm{III})$-hydride complex that would undergo deprotonation to reform the $\mathrm{Co}$ (I) form of $\mathrm{CarH}^{*}$. For B12 on the other hand, homolytic dissociation of $\mathbf{E}$ to generate a $\mathrm{Co}$ (II) species and the ethyl carboxymethyl radical that can add to styrene. While the resulting species could add back to $\mathrm{Co}$ (II) to re-enter the catalytic cycle as suggested by Gryko, ${ }^{10}$ polymerization dominates under different reaction conditions used in the current study.

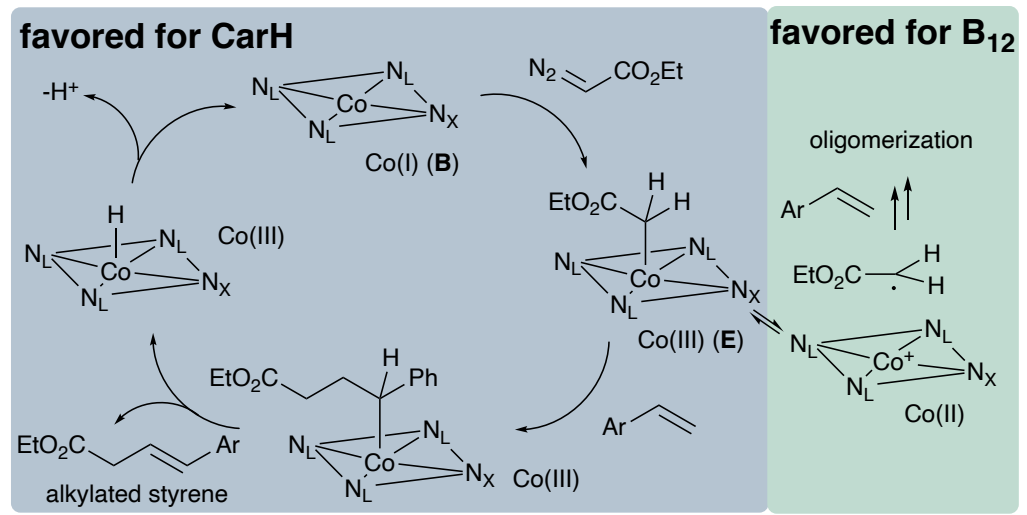

Figure 4. Mechanism of styrene alkylation (adapted from reference 10) accounting for differences in selectivity between $\mathrm{CarH}^{*}$ and free hydroxycobalamin.

\section{Conclusion}

B12-dependent enzymes are underutilized in biocatalysis relative to other metalloenzymes. Recent examples exploring the substrate scope of native B12-dependent enzyme catalysis ${ }^{4,34}$ and the broad range of reactions catalyzed by B12 cofactors $^{7}$ suggest that suitable systems could find broader application in biocatalysis. This study establishes that a B12-dependent enzyme can catalyze a transformation distinct from its native reaction. While the native function of $\mathrm{CarH}$ involves transcription regulation via AdoCbl homoloysis and $\beta$-hydride elimination to generate 4',5'didehydroadenosine, ${ }^{15,16,18,20} \mathrm{CarH}^{*}$ catalyzes styrene $\mathrm{C}-\mathrm{H}$ alkylation via non-native oxidative addition and olefin addition processes coupled with a native-like $\beta$-hydride elimination. Mechanistic studies on this reaction echo findings from earlier studies of AdoCbl homolysis in solution under strong cage conditions and in $\mathrm{CarH}$ itself to suggest that $\mathrm{CarH}^{*}$ can enable nonnative radical chemistry with improved selectivity relative to the B12 cofactor. ${ }^{16,26}$ These findings 
suggest that engineered $\mathrm{CarH}^{*}$ variants and perhaps related B12-dependent enzymes hold great promise as catalysts for a wide range of transformations.

\section{Supporting Information}

Supplemental figures, experimental and computational methods, and data for material characterization.

\section{Acknowledgements}

This study was supported by the U.S. Army Research Laboratory and the U.S. Army Research Office under Contract/Grant W911NF-19-1-0074 (to JCL), by the NIH (R01 GM115665 to JCL), and by the NSF (CHE-1808133 to LAB). Y.S.Z gratefully acknowledges receipt of a predoctoral fellowship from the Graduate Training Program in Quantitative and Chemical Biology at Indiana University (T32 GM131994). NMR data were acquired on a spectrometer funded by the NSF (MRI CHE-1920026) using a Prodigy probe that was partially funded by the Indiana Clinical and Translational Sciences Institute. MS data were acquired on a spectrometer funded by NSF Grant CHE1726633. We thank Dr. Yi Yi at the Nanoscale Characterization Facility at Indiana University for assistance in preparing and measuring samples for GPC.

\section{References}

(1) Banerjee, R.; Ragsdale, S. W. The Many Faces of Vitamin B12: Catalysis by CobalaminDependent Enzymes. Annu Rev Biochem 2003, 72 (1), 209-247.

https://doi.org/10.1146/annurev.biochem.72.121801.161828.

(2) Marsh, E. N. G.; Drennan, C. L. Adenosylcobalamin-Dependent Isomerases: New Insights into Structure and Mechanism. Curr Opin Chem Biol 2001, 5 (5), 499-505.

https://doi.org/10.1016/s1367-5931(00)00238-6.

(3) Ragsdale, S. W. Catalysis of Methyl Group Transfers Involving Tetrahydrofolate and B12. Vitamins \& Hormones 2008, 79, 293-324. https://doi.org/10.1016/s0083-6729(08)00410-x.

(4) Payne, K. A. P.; Quezada, C. P.; Fisher, K.; Dunstan, M. S.; Collins, F. A.; Sjuts, H.; Levy, C.; Hay, S.; Rigby, S. E. J.; Leys, D. Reductive Dehalogenase Structure Suggests a Mechanism for B12-Dependent Dehalogenation. 2015, 517 (7535), 513-516.

https://doi.org/10.1038/nature13901.

(5) Drennan, C. L.; Huang, S.; Drummond, J. T.; Matthews, R. G. How a Protein Binds B12: A 3.0 A X-Ray Structure of B12-Binding Domains of Methionine Synthase. Science 1994, 266, 1669-1674.

(6) Ludwig, M. L.; Matthews, R. G. Structure-Based Perspectives on B12-Dependent Enzymes. Annual Review of Biochemistry 1997, 66, 269-313.

(7) Giedyk, M.; Goliszewska, K.; Gryko, D. Vitamin B12 Catalysed Reactions. Chemical Society Reviews 2015, 44 (11), 3391-3404. https://doi.org/10.1039/c5cs00165j. 
(8) McCauley, K. M.; Pratt, D. A.; Wilson, S. R.; Shey, J.; Burkey, T. J.; Donk, W. A. van der. Properties and Reactivity of Chlorovinylcobalamin and Vinylcobalamin and Their Implications for Vitamin B 12-Catalyzed Reductive Dechlorination of Chlorinated Alkenes. Journal of the American Chemical Society 2005, 127 (4), 1126-1136. https://doi.org/10.1021/ja048573p.

(9) Shey, J.; McGinley, C. M.; McCauley, K. M.; Dearth, A. S.; Young, B. T.; Donk, W. A. van der. Mechanistic Investigation of a Novel Vitamin B 12-Catalyzed Carbon-Carbon Bond Forming Reaction, the Reductive Dimerization of Arylalkenes. Journal of Organic Chemistry 2002, 67 (3), 837-846. https://doi.org/10.1021/jo0160470.

(10) Giedyk, M.; Goliszewska, K.; Proinsias, K. ó; Gryko, D. Cobalt(I)-Catalysed CHAlkylation of Terminal Olefins, and Beyond. Chemical Communications 2016, 52 (7), 13891392. https://doi.org/10.1039/c5cc07363d.

(11) Chen, L.; Hisaeda, Y.; Shimakoshi, H. Visible Light-Driven, Room Temperature HeckType Reaction of Alkyl Halides with Styrene Derivatives Catalyzed by B 12Complex. Advanced Synthesis \& Catalysis 2019, 361 (12), 2877-2884. https://doi.org/10.1002/adsc.201801707.

(12) Ikeda, Y.; Nakamura, T.; Yorimitsu, H.; Oshima, K. Cobalt-Catalyzed Heck-Type Reaction of Alkyl Halides with Styrenes. Journal of the American Chemical Society 2002, 124 (23), 6514-6515. https://doi.org/10.1021/ja0262961.

(13) Schrauzer, G. N.; Deutsch, E.; Windgassen, R. J. The Nucleophilicity of Vitamin B12s. $J$ Am Chem Soc 1968, 90 (9), 2441-2442. https://doi.org/10.1021/ja01011a054.

(14) Dolphin, D. Preparation of the Reduced Forms of Vitamin B12 and of Some Analogs of the Vitamin B12 Coenzyme Containing a Cobalt-Carbon Bond. Methods Enzymol 1971, 18, 34-52. https://doi.org/10.1016/s0076-6879(71)18006-8.

(15) Ortiz-Guerrero, J. M.; Polanco, M. C.; Murillo, F. J.; Padmanabhan, S.; Elias-Arnanz, M. Light-Dependent Gene Regulation by a Coenzyme B12-Based Photoreceptor. Proceedings of the National Academy of Sciences 2011, 108 (18), 7565-7570. https://doi.org/10.1073/pnas.1018972108.

(16) Jost, M.; Simpson, J. H.; Drennan, C. L. The Transcription Factor CarH Safeguards Use of Adenosylcobalamin as a Light Sensor by Altering the Photolysis Products. Biochemistry 2015, 54 (21), 3231-3234. https://doi.org/10.1021/acs.biochem.5b00416.

(17) Baldwin, D. A.; Betterton, E. A.; Chemaly, S. M.; Pratt, J. M. The Chemistry of Vitamin B 12. Part 25. Mechanism of the $\beta$-Elimination of Olefins from Alkylcorrinoids; Evidence for an Initial Homolytic Fission of the Co-C Bond. Journal Of The Chemical Society-Dalton Transactions 1985, No. 8, 1613-1618. https://doi.org/10.1039/dt9850001613.

(18) Hardman, S. J. O.; Johannissen, L. O.; Bellina, B.; Messiha, H. L.; Ortiz-Guerrero, J. M.; as-Arnanz, M. E. iacute; Padmanabhan, S.; Barran, P.; Scrutton, N. S.; Kutta, R. J.; Jones, A. R. 
The Photochemical Mechanism of a B12-Dependent Photoreceptor Protein. Nature Communications 2019, 6 (1), 1-11. https://doi.org/10.1038/ncomms8907.

(19) Miller, N. A.; Kaneshiro, A. K.; Konar, A.; Alonso-Mori, R.; Britz, A.; Deb, A.; Glownia, J. M.; Koralek, J. D.; Mallik, L.; Meadows, J. H.; Michocki, L. B.; Driel, T. B. van; Koutmos, M.; Padmanabhan, S.; Elías-Arnanz, M.; Kubarych, K. J.; Marsh, E. N. G.; Penner-Hahn, J. E.; Sension, R. J. The Photoactive Excited State of the B12-Based Photoreceptor CarH. J Phys Chem B 2020, 124 (47), 10732-10738. https://doi.org/10.1021/acs.jpcb.0c09428.

(20) Jost, M.; Fernández-Zapata, J.; Polanco, M. C.; Ortiz-Guerrero, J. M.; Chen, P. Y.-T.; Kang, G.; Padmanabhan, S.; Elías-Arnanz, M.; Drennan, C. L. Structural Basis for Gene Regulation by a B12-Dependent Photoreceptor. Nature 2015, 526 (7574), 536-541.

https://doi.org/10.1038/nature14950.

(21) Lexa, D.; Saveant, J. M.; Zickler, J. Electrochemistry of Vitamin B12. 2. Redox and AcidBase Equilibria in the B12a/B12r System. J Am Chem Soc 1977, 99 (8), 2786-2790. https://doi.org/10.1021/ja00450a061.

(22) Hill, J. A.; Pratt, J. M.; Williams, R. J. P. The Chemistry of Vitamin B 12 . Part I. The Valency and Spectrum of the Coenzyme. J Chem Soc Resumed 1964, 0 (0), 5149-5153. https://doi.org/10.1039/jr9640005149.

(23) Lexa, D.; Savéant, J.-M. Brönsted Basicity of Vitamin B12s. J Chem Soc Chem Commun 1975, No. 21, 872-874. https://doi.org/10.1039/c39750000872.

(24) Chen, Y.; Zhang, X. P. Vitamin B 12Derivatives as Natural Asymmetric Catalysts: Enantioselective Cyclopropanation of Alkenes. Journal of Organic Chemistry 2004, 69 (7), 2431-2435. https://doi.org/10.1021/jo049870f.

(25) Quinn, D. M.; Sutton, L. D. Enzyme Mechanism from Isotope Effects. In Theoretical Basis and Mechanistic Utility of Solvent Isotope Effects; Cook, P. F., Ed.; 1991; pp 73-126.

(26) Garr, C. D.; Society, R. F. J. of the A. C. Radical Cage Effects in Adocobinamide (AxialBase-Off Coenzyme B12): A Simple Method for Trapping [Ado $\bullet$ CoII] Radical Pairs, A New Beta-H Elimination Product from the Radical Pair, and Measurement of an Unprecedentedly Large Cage-Recombination Efficiency Factor, Fc $>0.94$. Journal of the American Chemical Society 1992, 114 (26), 10440-10445. https://doi.org/10.1021/ja00052a045.

(27) Finke, R. G.; Hay, B. P. Thermolysis of Adenosylcobalamin: A Product, Kinetic, and Cobalt-Carbon (C5') Bond Dissociation Energy Study. Inorganic Chemistry 1984, 23 (20), 3041-3043. https://doi.org/10.1021/ic00188a002.

(28) Khersonsky, O.; Tawfik, D. S. Enzyme Promiscuity: A Mechanistic and Evolutionary Perspective. Annual Review of Biochemistry 2010, 79 (1), 471-505.

https://doi.org/10.1146/annurev-biochem-030409-143718. 
(29) Yang, Y.; Arnold, F. H. Navigating the Unnatural Reaction Space: Directed Evolution of Heme Proteins for Selective Carbene and Nitrene Transfer. Accounts Chem Res 2021, 54 (5), 1209-1225. https://doi.org/10.1021/acs.accounts.0c00591.

(30) Brandenberg, O. F.; Fasan, R.; Arnold, F. H. Exploiting and Engineering Hemoproteins for Abiological Carbene and Nitrene Transfer Reactions. Current Opinion In Biotechnology 2017, 47, 102-111. https://doi.org/10.1016/j.copbio.2017.06.005.

(31) Fernandez, P. L.; Murkin, A. S. Inverse Solvent Isotope Effects in Enzyme-Catalyzed Reactions. Molecules 2020, 25 (8), 1933. https://doi.org/10.3390/molecules25081933.

(32) Lexa, D.; Research, J. S. A. of C.; 1983. The Electrochemistry of Vitamin B12. Accounts Chem Res 1983, 16 (7), 235-243. https://doi.org/10.1021/ar00091a001.

(33) Pollard-Knight, D.; Cornish-Bowden, A. Solvent Isotope Effects on the Glucokinase Reaction. Eur J Biochem 1984, 141 (1), 157-163. https://doi.org/10.1111/j.1432-

1033.1984.tb08170.x.

(34) Grimm, C.; Lazzarotto, M.; Pompei, S.; Schichler, J.; Richter, N.; Farnberger, J. E.; Fuchs, M.; Kroutil, W. Oxygen-Free Regioselective Biocatalytic Demethylation of Methyl-Phenyl Ethers via Methyltransfer Employing Veratrol-O-demethylase. ACS Catal. 2020, 10 (18), 10375-10380. https://doi.org/10.1021/acscatal.0c02790.

TOC Graphic

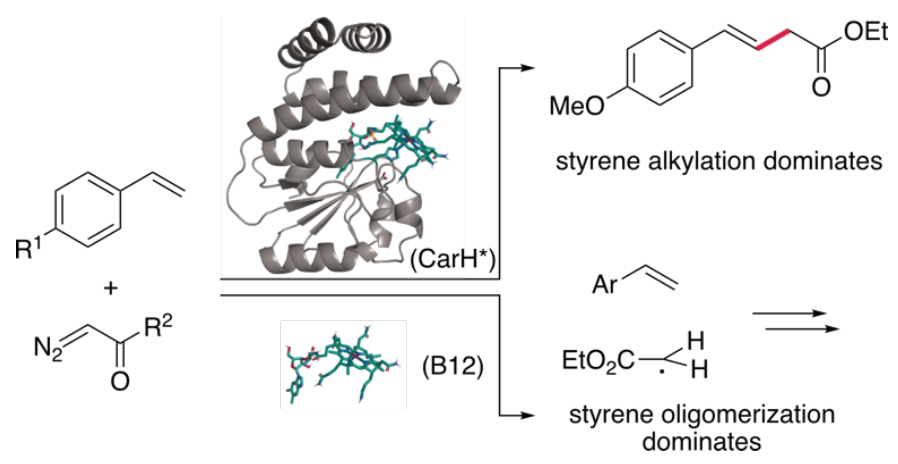

